\title{
Temas de Natureza da Ciência a partir de episódios históricos: os debates sobre a natureza da luz na primeira metade do século $\mathrm{XIX}^{+*}$
}

\author{
Rilavia Almeida de Oliveira ${ }^{1}$ \\ Universidade Estadual da Paraíba \\ André Ferrer Pinto Martins ${ }^{1}$ \\ Universidade Federal do Rio Grande do Norte \\ Natal - RN \\ Ana Paula Bispo da Silva ${ }^{1}$ \\ Universidade Estadual da Paraíba \\ Campina Grande - PB
}

\section{Resumo}

Este trabalho insere-se no contexto das discussões acerca da inserção da chamada "Natureza da Ciência" (NDC) no ensino de ciências por meio do uso da História e da Filosofia da Ciência (HFC). A partir da análise de aspectos dos debates sobre a natureza da luz no início do século XIX, propomos a discussão de diversos temas da NDC, com ênfase nos diferentes fatores envolvidos no processo de avaliação entre teorias concorrentes. Em particular, trazemos as contribuições de Thomas Young e Augustin Fresnel no âmbito da disputa entre a teoria ondulatória e corpuscular da luz, destacando, ainda, aspectos dos contextos francês e britânico desse periodo. Surgem, da apresentação desse episódio histórico, certos temas concernentes ao saber sobre ciência, tanto relacionados mais diretamente a questões históricas e sociológicas quanto relativos a questões epistemológicas, e que podem ser problematizados e explorados no ensino de física.

Palavras-chave: História e Filosofia da Ciência; Natureza da Ciência; Natureza da Luz.

\footnotetext{
${ }^{+}$Themes of the Nature of Sciences from a historical episode: the debates about the nature of light in the first half of the nineteenth century

* Recebido: outubro de 2019. Aceito: fevereiro de 2020.

${ }^{1}$ E-mails: rilavia.almeida@gmail.com; aferrer34@yahoo.com.br; silva.anapaulabispo@gmail.com
} 


\begin{abstract}
This paper works in the context of the discussions about the insertion of the "Nature of Science" (NOS) in the teaching of science through the use of the History and Philosophy of Science (HPS). Starting from the analysis of the aspects about the debate concerning the nature of light in the beginning of the nineteenth century, it is proposed the discussion of several themes of the Nature of Science (NOS), with emphasis in the different factors related to the process of evaluation between rival theories. Particularly, it is brought the contributions of Thomas Young and Augustin Fresnel concerning the dispute between the wave and corpuscular theory of light, highlighting the context of the British and the French aspects in this period. Some themes related to the knowledge about science emerge from the presentation of this historical episode, directly more related to the historical and sociological questions as well as concerning the epistemological questions that can be problematized and explored at the teaching of physics.
\end{abstract}

Keywords: History and Philosophy of Science; Nature of Science; Nature of Light.

\title{
I. Introdução
}

Um crescente número de documentos governamentais e de pesquisadores, nas últimas décadas, defendem o ensino de ciências de uma forma contextualizada, no qual o aluno deve aprender sobre as dimensões ética, social, histórica e filosófica da ciência, além de adquirir conhecimento científico. Nessa perspectiva, além de um saber em ciências, o aluno deve ter um conhecimento sobre as ciências, ou seja, um conhecimento sobre a Natureza da Ciência (NDC) (BRASIL, 1999, 2001, 2018; MATTHEWS, 1994, 2012; IRZIK; NOLA, 2014; MOURA, 2014; MARTINS, 2015).

Dentre as alternativas apresentadas como forma de inserir a NDC no ensino de ciências, a literatura tem evidenciado a relevância da História e da Filosofia da Ciência (HFC) como abordagem didática com potencial para discutir aspectos da NDC no ensino (RUDGE; HOWE, 2009; FORATO, 2009; FORATO; MARTINS; PIETROCOLA, 2012; MOURA, 2014; MARTINS, 2015).

Nesse sentido, dentro do contexto das pesquisas da área de ensino de ciências que abordam a interface entre HFC e NDC, este trabalho objetiva apresentar como o contexto histórico acerca das discussões sobre a natureza da luz no início do século XIX pode contribuir para a problematização de temas da NDC no ensino de ciências. Nesse intuito, inicialmente, analisamos fontes primárias (YOUNG, 1800, 1802a, 1802b, 1804; FRESNEL, 1819) e secun- 
dárias (FOX, 1974; SILLIMAN, 1974; FRANKEL, 1976, 1977; CANTOR, 1983; JAMES, 1984; CHEN, 1992; DARRIGOL, 2012; MOURA; BOSS, 2015), buscando caracterizar e compreender o episódio histórico e seus aspectos conceituais e epistemológicos. Em um segundo momento, buscamos identificar temas de NDC que podem ser trabalhados a partir do episódio histórico estudado, tomando como base a abordagem por "temas" e "questões" da NDC (MARTINS, 2015).

Sobre o estudo do episódio histórico, salientamos: 1) a necessidade de fazer recortes (FORATO, 2009) - foram analisados estudos sobre a natureza da luz na primeira metade do século XIX, especificamente com referência aos contextos francês e britânico; 2) que foram utilizadas as bases History of Science Society (HSS); JSTOR; Archive e a biblioteca Gallica ${ }^{2}$ na busca por fontes primárias e secundárias; dentre outros aspectos.

\section{Os debates sobre a natureza da luz na primeira metade do século XIX}

Ao longo de todo o século XVIII, diferentes concepções concorreram para tentar explicar a natureza da luz ${ }^{3}$. Apesar disso, havia um maior predomínio da teoria corpuscular da luz entre os estudiosos da época, especialmente na Grã-Bretanha. Em fins do século XVIII, contudo, as dificuldades inerentes à teoria corpuscular da luz se tornaram cada vez mais evidentes. A óptica newtoniana e os modelos mecânicos que foram desenvolvidos a partir dela não conseguiam mais explicar os vários fenômenos ópticos conhecidos à época, como, por exemplo, a dupla refração da luz.

No início do século XIX, o estudo de fenômenos como interferência, difração, dupla refração e polarização serviram como base para novos estudos e controvérsias ${ }^{4}$. Na tentativa de buscar explicações para os fenômenos luminosos, estudiosos da época trabalhavam, predominantemente, dentro de duas correntes sobre a natureza da luz: a teoria corpuscular e a teoria ondulatória. Cabe destacar, ainda, que a controvérsia entre essas teorias sobre a nature-

\footnotetext{
2 Link: https://hssonline.org/resources/hstm-database/; www.jstor.org; www.archive.org e https://gallica.bnf.fr.

3 Para mais detalhes dos estudos sobre natureza da luz ao longo do século XVIII, consultar: Moura (2008), Cantor (1983) e Darrigol (2012).

4 Adotamos o termo controvérsia seguindo a definição apresentada por Junges e Massoni (2018): Uma controvérsia científica é um tipo particular de disputa em que os protagonistas (cientistas) são membros de uma comunidade científica. Contudo, uma disputa ou um simples desacordo entre dois cientistas não é suficiente para constituir uma controvérsia científica. Mesmo que uma controvérsia inicie com dois indivíduos, ela é essencialmente uma atividade comunitária, de modo que outros membros da comunidade científica, com a competência necessária, podem tomar parte da disputa ou julgar os méritos de cada posição. Dessa forma, pode-se dizer que uma controvérsia científica existe apenas quando partes substanciais da comunidade científica reconhecerem que há mérito científico nos argumentos de ambos os lados de uma disputa pública entre cientistas (JUNGES; MASSONI, 2018, p. 460). Nesse sentido, podemos caracterizar os debates em torno da natureza da luz no início do século XIX como uma controvérsia científica, na medida em que essas discussões envolviam diferentes estudiosos da comunidade científica do período que debatiam, especialmente, perante as academias científicas da época, os méritos das duas correntes sobre a natureza da luz.
} 
za da luz também envolvia fatores políticos, filosóficos, dentre outros. É esse intrincado de ideias que procuraremos discutir no decorrer desta seção ${ }^{5}$.

\section{II.1 As contribuições de Thomas Young para o desenvolvimento da teoria ondulatória da luz}

Entre os estudiosos que contribuíram para as discussões sobre a natureza da luz no início do século XIX temos Thomas Young (1773-1829), físico, médico e egiptólogo britânico, que reativou ${ }^{6}$ as pesquisas em direção à teoria ondulatória da luz. Seu trabalho sobre essa teoria e sobre o princípio de interferência cobre um período de aproximadamente sete anos, entre 1800 e 1807.

Em sua teoria sobre a natureza da luz, Thomas Young defendeu a analogia com o som e o papel de um éter ubíquo ${ }^{7}$. Biograficamente, o significado da analogia com o som parece estar relacionado a seu conhecimento em medicina. Suas primeiras pesquisas exploraram os temas de acomodação visual (1793) e acústica (1800), ambas servindo como uma introdução para seu trabalho em óptica física.

O principal trabalho de Thomas Young em direção a sua teoria ondulatória da luz foi publicado em 1802, na Philosophical Transactions, intitulado "On the Theory of Light and Colours" (1802a). Nesse, Young traz uma versão inicial de seu princípio de interferência:

Quando duas Ondulações, a partir de diferentes origens, coincidem perfeitamente ou quase [coincidem] em Direção, seu efeito conjunto é uma Combinação dos Movimentos pertencentes a cada uma [delas] (YOUNG, 1802a, p. 34 apud MOURA; BOSS, 2015, p. 16).

Young tomou o princípio de interferência como sua principal defesa da teoria ondulatória da luz. Além disso, nesse trabalho, ele traz uma discussão inicial em torno do fenômeno de difração ${ }^{9}$ (inflexão, nas palavras de Young).

\footnotetext{
5 Este artigo faz parte de uma pesquisa maior na qual construímos um episódio mais extenso e elaborado. Para um maior aprofundamento sobre o episódio histórico retratado nesta seção, consultar: Oliveira (2019).

${ }^{6}$ Historiadores, em geral, classificam as teorias do século XVIII como vibracionais e não como ondulatórias, uma vez que estas defendiam a ideia de vibrações através de pulsos de luz. Nesse sentido, Thomas Young teria reativado pesquisas ondulatórias que remontam a Christiaan Huygens que, ainda no século XVII, defendia a ideia de ondas na propagação da luz.

${ }^{7} \mathrm{O}$ modelo de éter, inicialmente defendido por Young, presumia este constituído de partículas que se repeliam, mas que eram atraídas pela matéria dos corpos. Assim, corpos mais densos possuíam mais éter, ficando rodeados de uma atmosfera etérea (MOURA; BOSS, 2015).

8 Este trabalho de Young encontra-se traduzido para a língua portuguesa e está disponível em Moura e Boss (2015).

${ }^{9} \mathrm{Na}$ tentativa de estabelecer a teoria ondulatória da luz, o fenômeno de difração era de particular interesse. Se pudesse ser mostrado que a luz desvia de seu curso retilíneo, curvando-se em torno de obstáculos, a maior objeção à teoria ondulatória seria removida, uma vez que corpuscularistas, desde a época de Newton, se baseavam na propagação aparentemente retilínea da luz para criticar qualquer teoria que defendesse a luz como uma propagação em um determinado meio.
} 
Ao discutir a formação de cores pela inflexão, Young afirma que, ao passar através de uma pequena abertura, a luz mais próxima de seu centro deve ser a menos desviada e a luz mais próxima de suas bordas a mais desviada. A luz que incide muito obliquamente sobre a margem da abertura será refletida em várias direções. Assim, algumas coincidirão perfeitamente, ou quase, em direção com a luz não refletida. A interferência dessas duas porções de luz provocaria uma aparência de cores (YOUNG, 1802a apud MOURA; BOSS, 2015).

As franjas coloridas ocasionadas pela difração na borda de um disco, por sua vez, seriam decorrentes da interferência entre o raio infletido pela atmosfera em torno da borda e o raio refletido pela superfície da borda (Fig. 1).

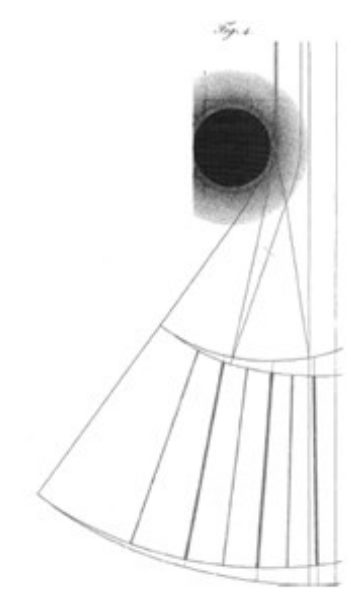

Fig. 1 - Ilustração de Young para discutir a "inflexão" da luz, atualmente chamada difração. Fonte: MOURA; BOSS, 2015, p. 20.

Outro aspecto a destacar nesse trabalho de Young é que ele procurou minimizar as objeções dos defensores da teoria corpuscular contra a teoria ondulatória. Nesse intuito, ele procurou trazer a impressão de concordância com as ideias de Newton, citando extratos de escritos desse estudioso em suporte às suas hipóteses básicas. Fez cortes constantes nos tre$\operatorname{chos}^{10}$, omitindo frases e parágrafos, com o intuito de encaixar as ideias de Newton (que era contrário à teoria ondulatória da luz) com sua argumentação (JAMES, 1984; DARRIGOL, 2012; MOURA; BOSS, 2015).

Na sequência, Young publicou mais dois trabalhos na Philosophical Transactions "An Account of Some Cases of the Production of Colours, not Hitherto Described" (1802b) e "The Bakerian Lecture: Experiments and Calculations Relative to Physical Optics" (1804), buscando uma "comprovação" experimental do princípio de interferência. Cabe ressaltar que, nesses dois trabalhos, Young se concentra na aplicação da lei de interferência a diversos fenômenos, como a formação de franjas resultantes da difração, arco íris, entre outros, uma vez

\footnotetext{
10 Para melhor entendimento do uso de Young das ideias de Newton para corroborar suas hipóteses consultar Moura e Boss (2015).
} 
que ele considerava as numerosas e bem-sucedidas aplicações de sua lei de interferência como prova em favor da teoria ondulatória da luz.

Young defendeu que qualquer que fosse a opinião sobre a teoria da luz e das cores que ele havia submetido à Royal Society, dever-se-ia admitir que ela permitiu a descoberta de uma lei simples e geral capaz de explicar uma série de fenômenos de luz colorida que, sem esta lei, permaneceriam inexplicáveis (YOUNG, 1802b). Dessa maneira, ele apresentou o princípio de interferência como lei, como segue:

Sempre que duas porções da mesma luz atinjam o olho por caminhos diferentes, ambos exatamente ou quase exatamente na mesma direção, a luz torna-se mais intensa quando a diferença de rotas é qualquer múltiplo de um certo comprimento, e menos intensa no estado intermediário das porções em interferência; e este comprimento é diferente para luz de diferentes cores (YOUNG, 1802b, p. 387).

No trabalho de 1804, cabe destacar a inferência argumentativa a respeito da natureza da luz proposta por Young:

\begin{abstract}
Desses experimentos e cálculos que tem sido observados, podemos ser autorizados a inferir que luz homogênea [...] se move mais lentamente em um meio mais denso, que em um meio mais raro; e isto sendo reconhecido, deve ser admitido que refração não é o efeito de uma força atrativa dirigida para um meio mais denso. Os defensores da hipótese de projétil da luz devem refletir qual elo de raciocínio eles podem julgar ser o mais fraco nesta sequência; pois, até agora, eu não tinha avançado neste trabalho nenhuma hipótese geral qualquer. Mas, visto que conhecemos que som diverge em superficies concêntricas e que som musical consiste em qualidades opostas, capazes de neutralizar uma a outra, sucedendo em certos intervalos iguais, que são diferentes conforme a diferença de nota, estamos totalmente autorizados a concluir que deve haver alguma grande semelhança entre a natureza do som e essa da luz (YOUNG, 1804, p. 11-12).
\end{abstract}

$\mathrm{O}$ argumento utilizado por Young, no trecho anterior, baseia-se no fato de que a luz devia mover-se mais devagar no meio mais denso, o que contrariava o pressuposto usado para explicar a refração na teoria corpuscular. Logo, a luz deveria ser uma ondulação no éter luminoso (MORSE, 2007; DARRIGOL, 2012).

Entre os principais aspectos dos trabalhos de Young, podemos ressaltar que ele: 1) recorre sempre a analogias para explicar os fenômenos luminosos, como a analogia com fluidos, corpos elásticos e, principalmente, a analogia com o som; 2) defende a realização de experimentos para corroborar as conjecturas feitas acerca dos fenômenos luminosos (defesa muito recorrente em seu trabalho), no entanto, a maioria das considerações em que menciona experimentos são teóricas ou citando experimentos realizados por outros estudiosos; 3) não se utiliza de formulações algébricas, mas de raciocínios geométricos; 4) cita o nome de outros estudiosos, a exemplo de Huygens, Newton e Euler. 
Em relação à repercussão, é importante destacar que a despeito dos trabalhos de Young, estudiosos da época continuaram a defender a teoria corpuscular da luz. Não há um consenso entre os historiadores quanto aos fatores que contribuíram para um predomínio da teoria corpuscular no meio científico por duas décadas após os trabalhos de Young na teoria ondulatória da luz. Nesse sentido, apesar de reconhecer as deficiências nos trabalhos de Young sobre difração e interferência, salientamos que o contexto predominantemente newtoniano no qual ele escreveu seus trabalhos também não pode ser desconsiderado. Nesse contexto, havia forte rejeição ao uso de hipóteses ${ }^{11}$ na construção do conhecimento e, consequentemente, rejeição ao éter.

Após os trabalhos de Young, destaca-se Fresnel no retorno ao estudo dos fenômenos de interferência e uma busca pela óptica ondulatória. A década anterior ao início do trabalho de Fresnel na teoria ondulatória - 1805-1815 - é marcada, na França, pelo desenvolvimento de pesquisas dentro do programa laplaciano, especialmente, dentro da teoria corpuscular da luz.

\section{II.2 Desenvolvimentos na teoria corpuscular da luz dentro do programa laplaciano de pesquisa}

Na França, os estudos sobre a natureza da luz no início do século XIX estiveram associados ao chamado programa laplaciano de pesquisa. O programa de Laplace era visto, por seus praticantes, como uma culminação dos trabalhos do século XVIII na tradição newtoniana. Entre 1805 e 1815, o programa levantou problemas e estabeleceu princípios gerais para solução, dando unidade em estilo e propósito à física francesa. Um fator importante para o domínio do programa laplaciano se deve à eficácia com que Pierre Simon Laplace (17491827) e Claude Louis Berthollet (1748-1822) controlavam os estabelecimentos científicos em ensino e pesquisa da época, na França (FOX, 1974).

Nesse período, estudiosos franceses se reuniam na Sociedade de Arcueil. Dirigida por Berthollet e Laplace, a Sociedade era composta por jovens físicos e químicos de Paris: Jean-Baptiste Biot (1774-1862), Simeon Denis Poisson (1781-1840), Etienne Louis Malus (1775-1812), Dominique Francois Arago (1786-1853), dentre outros. Esses estudiosos, educados em laboratório e matemática na recém-fundada École Polytechnique, procuravam combinar o cálculo com a experiência para obter o máximo de precisão possível (FRANKEL, 1976, 1977).

A física laplaciana procurava descrever todo fenômeno, seja na escala terrestre, molecular ou celeste, em termos de forças centrais entre partículas que, embora tratadas por analogia com forças de gravitação newtonianas, podiam ser ou atrativas ou repulsivas ${ }^{12}$. As for-

\footnotetext{
11 Por "hipótese" entendia-se qualquer proposição que fizesse referência a entidades e processos não observados ou qualquer proposição que não pudesse ser verificada por indução.

12 A física laplaciana influenciou vários estudos na época além da óptica, como na eletrodinâmica e estudos sobre calor (GILLISPIE, 2007).
} 
ças eram consideradas como sendo exercidas sobre matéria imponderável tanto quanto sobre matéria ponderável.

A óptica corpuscular foi fundamental na física laplaciana, oferecendo muitos temas de pesquisa para o grupo de Arcueil. O interesse de Laplace pelas forças de curto alcance influenciou a maior parte das pesquisas em óptica feita por físicos franceses nos anos 1805 1808 (FOX, 1974; DARRIGOL, 2012).

Em 1807, um estudo matemático da dupla refração ${ }^{13}$ foi proposto como tema do prêmio a ser concedido a matemáticos na competição bianual de prêmios da Academie des Sciences de Paris. Foi um defensor da teoria corpuscular da luz e um dos discípulos de Laplace em Arcueil, Malus, que recebeu o prêmio com uma memória lida em 4 de junho de 1808 .

A pesquisa de Malus sobre a dupla refração teve duas consequências importantes para a teoria corpuscular: 1) através de uma série de experimentos apoiados por análises matemáticas, Malus confirmou a lei para a direção do segundo raio (extraordinário) no cristal da Islândia, que havia sido proposta por Huygens no século XVII ${ }^{14}$; 2) Malus também estudou a polarização por reflexão. Ele notou que as propriedades assimétricas que a luz duplamente refratada exibe poderiam ser produzidas pela simples reflexão em qualquer meio transparente e, portanto, seriam o resultado de alguma modificação fundamental da luz em sua interação com a matéria (FRANKEL, 1976).

Malus defendia que a descoberta do que mais tarde ele chamaria de polarização por reflexão decidiria a natureza da luz. Segundo Malus, as observações mostraram que o fenômeno de reflexão difere para o mesmo ângulo de incidência, o que não pode acontecer na hipótese de Huygens. Assim, ele defendia que a luz não é apenas uma substância submetida a forças que animam outros corpos, mas também a forma e disposição das moléculas de luz tem uma grande influência sobre o fenômeno (DARRIGOL, 2012).

A polarização transformou-se em um tópico importante de pesquisa para estudiosos interessados na óptica. Malus, Arago, Biot e David Brewster (1781-1868) desenvolveram trabalhos sobre polarização, nos anos que se seguiram aos estudos de Malus (FRANKEL, 1976; DARRIGOL, 2012).

Em relação à repercussão das novas pesquisas dentro da teoria corpuscular, em especial, relacionadas ao fenômeno de polarização, em 1810, Young admitiu que o teor geral desses fenômenos (polarização) é tal que aponta para alguma propriedade semelhante à polaridade, o que parece ser muito mais fácil de conciliar com as ideias newtonianas do que com as de Huygens (MORSE, 2007).

\footnotetext{
13 O fenômeno da dupla refração da luz, hoje tomado como um caso de polarização, foi estudado, inicialmente, por Bartholinus que, em 1669, tornou-se o primeiro a registrar que um pequeno objeto parece duplo quando visto através de duas faces opostas de um cristal de calcita. Quando um raio incide sobre tal cristal é, em geral, dividido em dois raios refratados. Um desses raios, chamado raio comum, obedece à lei usual de refração, enquanto o outro não e, portanto, é chamado de raio extraordinário.
}

14 Esse era um dos principais problemas não respondido pela óptica de Newton. 
Em 1815, Young teria admitido para David Brewster sua crescente perplexidade sobre o fenômeno de polarização, admitindo que conforme aprendia mais sobre os fatos que Malus tinha descoberto tornava-se menos convicto de sua hipótese sobre a natureza ondulatória da luz, uma vez que, embora sua hipótese sobre a natureza da luz não fosse incompatível com esses fenômenos, não permitia explicá-los. Mas, isso não se estendia a sua lei de interferência (DARRIGOL, 2012).

Enfim, o programa laplaciano de pesquisa ${ }^{15}$ estendeu o paradigma corpuscular da luz dentro da França, na década de 1805-1815. No entanto, é necessário mencionar, como salienta Frankel (1976), que a teoria também tinha problemas. Vários movimentos rotacionais e oscilatórios atribuídos aos corpúsculos leves, por exemplo, foram hipóteses ad hoc acrescentadas para explicar efeitos particulares. É esse contexto que marca o início das pesquisas de Fresnel na teoria ondulatória da luz, a qual discutiremos a seguir.

\section{II.3 A teoria ondulatória de Augustin Fresnel}

Durante seus estudos na École Polytechnique, Augustin Fresnel (1788-1827) tinha sido exposto à doutrina do calórico e a analogias entre calor e luz como diferentes estados desse fluido imponderável. No entanto, Fresnel rejeitou a substancialidade do calor. Para ele, seria mais natural pensar que calor e luz eram devidos apenas a vibrações no calórico - luz e calor podiam ser melhor explicados utilizando o conceito de ondas (SILLIMAN, 1974; LEVITT, 2000; DARRIGOL, 2012).

Fresnel começou seus estudos na teoria ondulatória a partir de experimentos sobre franjas de difração. Em seu primeiro livro de memórias sobre difração, enviado à Academie des Sciences, em outubro de 1815, Fresnel repetiu muitos aspectos do trabalho anterior de Young $_{17}^{16}$ Arago, então, desempenhou um papel crucial ao se tornar relator das memórias de Fresnel ${ }^{17}$.

Em 25 de março de 1816, Arago leu perante a Academie des Sciences um relatório sobre o trabalho de Fresnel. Esse relatório enfatizou a engenhosidade das observações e estimulou a Academia a reconhecer o seu valor sem se pronunciar sobre o mérito da hipótese ondulatória. Arago também publicou a memória de Fresnel na Annales de Chimie et de Physique. No entanto, a memória sofreu diversas modificações. Enquanto Fresnel havia começado sua memória original com uma ampla discussão da plausibilidade física dos corpús-

\footnotetext{
15 Para mais detalhes do programa Laplaciano de pesquisa e dos desenvolvimentos da teoria corpuscular dentro deste, consultar: Fox (1974), Frankel (1976).

16 É necessário esclarecer que, nessa época, Fresnel estava pouco familiarizado com as teorias anteriores que concebiam a luz como ondas ou pulsos (SILLIMAN, 2007).

17 François Arago, anteriormente, trabalhava junto aos laplacianos. No entanto, a partir de 1812, disputas com Biot sobre a prioridade nos estudos sobre a despolarização afastaram Arago do grupo de Laplace na Academie des Sciences. Arago se tornou o principal defensor de Fresnel na referida instituição, divulgando a teoria ondulatória na comunidade científica francesa.
} 
culos e das ondas, a versão da Annales omitiu toda discussão das duas teorias como hipóteses físicas. Essa versão da Annales partiu diretamente para a discussão da configuração experimental e seguiu alternando resultados experimentais com a explicação quantitativa providenciada pelo tratamento matemático de Fresnel (LEVITT, 2000).

Em sua divulgação do trabalho inicial, Arago enfatizou os desenvolvimentos experimentais de Fresnel, no entanto, não enfatizou sua hipótese em defesa da teoria ondulatória da luz. Conjecturamos que Arago deveria estar evitando um enfrentamento com os laplacianos, defensores da teoria corpuscular da luz, que até então dominavam as instituições científicas.

Nessa época (1816), Biot apresentou a Academia um extenso trabalho corpuscular sobre difração, que ele e Claude Pouillet (1790-1868) prepararam como um suplemento ao quarto volume de seu Traité de Physique. Nesse trabalho, eles discutiram as peculiaridades dos padrões de diferentes obstáculos de difração. Biot relacionou a regularidade do espaçamento das faixas de difração de diferentes cores com a regularidade dos anéis de Newton e defendeu que estes devem ser produzidos por estados de fácil reflexão e refração (FRANKEL, 1976).

Em 1817, a difração foi proposta como tema da competição bianual de prêmios de física da Academie des Sciences. A despeito de, entre os cinco jurados, estarem o próprio Laplace e dois laplacianos, Biot e Poisson, Fresnel ganhou o prêmio, em março de 1819, com um extenso trabalho sobre difração, intitulado Mémoire sur la diffraction de la lumière.

Esse trabalho encontra-se dividido em três seções: 1) discussão sobre a insuficiência da teoria corpuscular e da visão de Young a respeito da interferência; 2) o fenômeno de difração explicado pela combinação do princípio de Huygens com o princípio de interferência e 3) sobre a interferência da luz polarizada (FRESNEL, 1819).

Tomando como base o argumento que a explicação da teoria corpuscular acerca do fenômeno de difração, a saber, a formação das franjas externas devido a uma força que é alternadamente atrativa e repulsiva, e cuja fonte está na superfície do corpo produzindo as sombras, não se encaixava com dados experimentais, bem como a inadequação da explicação de Young de que as franjas de difração resultam de raios infletidos tendo sua origem na superfície do corpo difrator ou nos pontos infinitamente próximos a esta, Fresnel busca explicar o fenômeno de difração tomando como base o princípio de Huygens ${ }^{18}$ e o princípio de interferência:

Agora, proponho apresentar que podemos encontrar uma explicação satisfatória e uma teoria geral em termos de ondas, sem recurso a qualquer hipótese auxiliar, baseando tudo sobre o principio de Huygens e sobre esse de interferência, ambos dos quais são inferências da hipótese fundamental (FRESNEL, 1819).

\footnotetext{
18 De acordo com o princípio de Huygens, um pulso de luz gerado por um corpo luminoso gera pulsos secundários nas partículas subsequentes, preservando o movimento (MOURA; BOSS, 2015).
} 
Em suma, Fresnel analisou o problema de difração em termos de uma onda espalhando a partir da fonte tal que, em concordância com a construção de Huygens, cada ponto na frente de onda é a própria fonte de ondas secundárias. Para determinar a intensidade da luz em qualquer ponto na tela, Fresnel adicionou as contribuições de todas essas ondas secundárias, empregando o princípio de interferência que levou em consideração as relações de fase envolvidas. O cálculo da intensidade de vibração da onda resultante em determinado ponto é obtido através de complicados cálculos algébricos, envolvendo integrais e diferenciais.

Um dos jurados da competição de difração proposta pela Academie des Sciences, Poisson, apontou a previsão inesperada da teoria de Fresnel de que no centro da sombra de um disco circular deveria haver um ponto brilhante, decorrente da soma dos efeitos de todas as ondas secundárias em fase provenientes de todos os pontos da borda do disco. A predição foi confirmada experimentalmente por Arago, mostrando assim o poder explicativo e a habilidade preditiva da teoria de Fresnel (JAMES, 1984; SILLIMAN, 2007).

Com a vitória do trabalho de Fresnel nessa competição, a teoria ondulatória obteve uma importante vitória pública - a explicação de interferência na difração teve de ser reconhecida, pelo menos publicamente, pelos corpuscularistas franceses (FRANKEL, 1976).

Confirmações do poder preditivo da teoria de Fresnel, no entanto, não foram suficientes para converter Laplace e seus discípulos à teoria ondulatória da luz. Outro desafio para a teoria ondulatória foi a integração do fenômeno de polarização.

Fresnel começou a estudar sobre a polarização e os efeitos da coloração em cristais finos no verão de 1816. Naquela época, ele tentou produzir interferência entre os raios comuns e extraordinários de luz duplamente refratada e não obteve sucesso. Fresnel e Arago focaram nesse problema, desenvolvendo diferentes experimentos para tratar o fenômeno. Ao mesmo tempo, Fresnel e seu amigo Ampère começaram a suspeitar que o fenômeno podia estar relacionado à característica transversal de pelo menos parte das vibrações ${ }^{19}$ (DARRIGOL, 2012; SILLIMAN, 2007).

Através de seus estudos sobre polarização, Fresnel ficou convencido que as vibrações que constituem luz só podiam ser transversais, uma vez que as características da luz polarizada mostravam a existência de forças agindo perpendicularmente aos raios. Assim, em um artigo publicado em 1821, Fresnel passou a argumentar que a luz era constituída inteiramente de vibrações transversais puras, convencido de que tal solução era necessária e conformada aos princípios mecânicos (CANTOR, 1983; SILLIMAN, 2007; DARRIGOL, 2012).

O problema que permaneceu para a teoria das ondas foi determinar como as ondas transversais poderiam ser propagadas em um éter fluido. As únicas ondas transversais conhe-

\footnotetext{
19 Segundo Morse (2007), em janeiro de 1817, Young já havia sugerido a Arago que a polarização poderia ser explicada pela suposição de que ela era um componente transversal diminuto, acrescentado à ondulação longitudinal do éter, que ele presumia ser a luz. Em setembro de 1817, ao escrever um artigo intitulado "Chromatics", Young elaborou a sugestão qualitativa de que um pequeno componente transversal de vibração poderia explicar as realidades da reflexão parcial. No entanto, não defendeu que as vibrações pudessem ser inteiramente transversais.
} 
cidas eram as ondas mecânicas em sólidos, cujas rigidez e elasticidade estavam diretamente relacionadas à velocidade de propagação da onda no meio. Assim, a imensa velocidade de propagação da luz implicava acreditar que o éter fosse um meio extremamente tênue e leve, porém, extremamente rígido e elástico.

Fresnel, então, supôs um modelo de éter ${ }^{20}$ que permitisse vibrações transversais e proibisse vibrações longitudinais. Esse modelo consistia de uma rede de moléculas mantidas em equilíbrio por forças à distância. As forças poderiam ser tais que um pequeno deslocamento transversal de uma camada plana de moléculas implicaria uma força de restauração proporcional, enquanto que os deslocamentos por um múltiplo da metade da distância intermolecular levariam a outra configuração de equilíbrio. O meio seria rígido em relação a minúsculas vibrações e fluido em relação a deslocamentos maiores. Em adição, Fresnel supunha que as forças intermoleculares podiam ser tais que uma força muito grande poderia ser necessária para mudar a distância entre duas camadas de moléculas sucessivas. Essa suposição excluía vibrações longitudinais (DARRIGOL, 2012, p.210).

Ao adotar a propagação transversal das ondas de luz, Fresnel conseguiu novos resultados. Entre eles, a previsão da direção de cada raio no espaço, sua intensidade, seu grau e direção de polarização e o ângulo de polarização para um dado meio. Assim, todos os fenômenos de reflexão e refração, exceto dispersão, tornaram-se consequências diretas de uma única teoria. Fresnel também conseguiu explicar novos tipos de polarização que Biot, Brewster e ele mesmo tinham observado na luz refletida e na luz transmitida através de lâminas de cristal (DARRIGOL, 2012; FRANKEL, 1976).

Em relação à recepção inicial da óptica de Fresnel, a teoria ondulatória da luz foi bem aceita ainda na década de 1820, na França. Entre os fatores que contribuíram para essa aceitação, podemos destacar o declínio do programa laplaciano de pesquisa dentro das instituições de pesquisa e divulgação francesas nesse período.

$\mathrm{Na}$ Grã-Bretanha, a teoria ondulatória de Fresnel tornou-se amplamente conhecida na década de 1820, através de palestras e publicações. No entanto, a teoria corpuscular da luz ainda prevalecia entre estudiosos britânicos nesse período. Dessa maneira, durante a década de 1830, diversos estudiosos britânicos e irlandeses ainda divergiam sobre a questão da natureza da luz.

\section{II.4 Discussões sobre a natureza da luz entre os britânicos na década de 1830}

Ao longo da década de 1830, o debate entre teoria ondulatória e teoria corpuscular da luz envolvia o estudo de fenômenos como dispersão e absorção da luz. Historiadores apontam diversos fatores que influenciaram nesta "disputa" teoria ondulatória versus teoria corpuscular

\footnotetext{
20 Para mais detalhes sobre as discussões em torno do éter ao longo do século XIX, consultar: Koehler, Camel e Pimentel Jr. (2012).
} 
e a subsequente "vitória" da teoria ondulatória, entre eles fatores políticos, conceituais e filosóficos.

Entre os fatores conceituais, a teoria ondulatória ainda não conseguia explicar importantes categorias de resultados experimentais, como absorção e dispersão.

Entre os fatores epistemológicos, dentro da tradição empirista predominante entre os britânicos, o uso de hipóteses na construção do conhecimento não era aceito pela maioria dos estudiosos do período. Portanto, a ideia de um éter permeando a propagação das ondas de luz ainda não era bem aceita entre os britânicos da época, uma vez que a existência desse meio não poderia ser comprovada experimentalmente, principal defesa nesse contexto empirista.

Entre os fatores políticos, temos o papel da British Association for the Advancement of Science. Dentro de poucos anos depois que foi fundada, em 1831, a Associação tornou-se uma importante instituição para a controvérsia corpuscular-ondulatória.

O encontro da Associação de 1833 ocorreu em Cambridge, reduto da teoria ondulatória. William Whewell, defensor da teoria ondulatória, foi eleito presidente do encontro e, devido à influência dos físicos de Cambridge, Lloyd foi escolhido como relator das novas pesquisas em óptica nesse encontro. Em seu relatório, Lloyd tratou de diversos fenômenos ópticos associados à luz polarizada e à luz não polarizada, buscando argumentar que a teoria ondulatória deveria ser aceita e a teoria corpuscular rejeitada. O relatório de Lloyd providenciou amplo suporte à teoria ondulatória e assegurou o controle da teoria ondulatória na Associação Britânica (CANTOR, 1983; CHEN, 1992).

Emissionistas $^{21}$, no entanto, continuaram a desafiar a teoria ondulatória. Eles procuravam explorar fenômenos que nem a teoria ondulatória nem a teoria emissionista conseguiam explicar. Entre eles, os debates sobre absorção, polarização e propriedades químicas da luz iniciados por emissionistas durante as décadas de 1830 e 1840 (CHEN, 1992).

Uma completa aceitação da teoria ondulatória só aconteceu por volta da metade do século. Chen (1992) atribui esse predomínio da teoria ondulatória ao surgimento de uma nova geração de ondulacionistas. Segundo ele, toda a velha geração de ondulacionistas era de newtonianos. As investigações ópticas de Young, por exemplo, consistiam principalmente em uma extensão, mais do que uma refutação, dos trabalhos ópticos de Newton (CHEN, 1992).

A nova geração dos ondulacionistas defendeu a teoria ondulatória bem no início de suas carreiras, quando eles não tinham familiaridade com a tradição emissionista. De um modo geral, a intensidade da controvérsia corpuscular-ondulatória diminui expressivamente na década de 1850 (CHEN, 1992). Ninguém tentou recuperar os resultados mais específicos de Fresnel num quadro newtoniano. Nenhum dos físicos da geração mais jovem aceitou a teoria corpuscular (DARRIGOL, 2012).

\footnotetext{
21 Gostaríamos de esclarecer que "emissionistas", "corpuscularistas”, entre outras, são as várias denominações dadas por historiadores aos estudiosos que defendiam a teoria corpuscular da luz.
} 


\section{Possibilidades para problematizar temas da Natureza da Ciência}

No intuito de investigar como o episódio histórico abordado anteriormente pode contribuir para a discussão de aspectos da NDC no ensino de ciências, tomamos como base a proposta de Martins (2015) que sugere trabalhar aspectos da NDC a partir de temas e questões, em vez de princípios de caráter geral. Martins (2015) apresenta os temas a partir de dois eixos principais ${ }^{22}$ :

[...] o eixo histórico e sociológico e o eixo epistemológico. O primeiro eixo agruparia temas relativos ao papel do indivíduo e da comunidade cientifica; a intersubjetividade; questões morais, éticas e politicas; influências históricas e sociais; ciência como parte da cultura; comunicação do conhecimento. O segundo eixo, mais amplo, agruparia temas relativos à origem do conhecimento (experiência x razão; papel da observação, da experiência, da lógica e do pensamento teórico; influência da teoria sobre o experimento), aos métodos, práticas, procedimentos e processos da ciência (coleta, análise e avaliação de dados; inferência, correlação e causalidade; modelagem em ciência; papel da imaginação e criatividade; natureza da explicação), e ao conteúdo/natureza do conhecimento produzido (papel de leis e teorias; noção de modelo; semelhanças e diferenças entre ciência e outras formas de conhecimento) (MARTINS, 2015, p. 718).

Cabe ressaltar que esses dois grandes eixos estão inter-relacionados, uma vez que "os aspectos propriamente epistêmicos e que caracterizam a 'natureza' do conhecimento produzido provêm de uma construção que é coletiva (intersubjetiva), histórica e social" (MARTINS, 2015, p. 718, grifos do autor).

Os temas de NDC devem ser considerados a partir de questões ${ }^{23}$, que contribuem para esclarecer o significado e o tratamento que podem ser dados aos temas, enfatizando o caráter investigativo que essa abordagem deve adotar (MARTINS, 2015).

\section{III.1 Metodologia de identificação dos temas de NDC}

A busca dos temas de NDC que podem ser trabalhados a partir do episódio histórico estudado foi dividida em duas etapas principais. Na primeira etapa, foram identificados os temas de NDC que poderiam ser trabalhados a partir da discussão de aspectos envolvidos no episódio histórico estudado, tomando como base os temas propostos em Martins (2015).

Na segunda etapa, agora já com diversos temas de NDC identificados, voltou-se novamente à leitura do episódio histórico buscando aspectos que permitissem a discussão de temas de NDC que não tinham sido explorados na primeira etapa da análise. Assim, nessa segunda etapa buscamoks identificar temas de NDC que podem ser trabalhados a partir do

\footnotetext{
22 Para mais detalhes, consultar Martins (2015, tabela 1, p. 719).

23 Para maiores detalhes, consultar tabela 2, constante a partir da página 721 do trabalho de Martins (2015) com exemplos de questões de NDC que podem ser discutidas a partir de cada tema dentro dos dois eixos principais.
} 
episódio histórico e que não estão presentes entre os temas de NDC propostos em Martins (2015).

\section{III.2 Temas de NDC obtidos a partir da primeira etapa de análise}

Dentro do eixo sociológico e histórico, podemos discutir os seguintes temas de NDC a partir do episódio histórico estudado:

- Papel dos indivíduos/sujeitos e da comunidade científica: a influência que a comunidade científica exerce no desenvolvimento dos conhecimentos científicos pode ser discutida, uma vez que percebemos que os estudiosos envolvidos nos estudos sobre natureza da luz no início do século XIX não trabalhavam isoladamente. Mas, ao invés disso, desenvolviam seus estudos sob a influência de grupos ou programas de pesquisa vigentes no período. Exemplo de questões a serem trabalhadas: Que papel você atribui às sociedades científicas no desenvolvimento da ciência, nesse período? Quais grupos foram mais relevantes?

- Questões morais, éticas e políticas: 1) predomínio do programa laplaciano de pesquisa nas instituições científicas de Paris contribuiu para o predomínio e expansão da teoria corpuscular da luz nas duas primeiras décadas do século XIX; 2) a aceitação da teoria ondulatória entre os franceses e britânicos foi permeada por fatores políticos. Exemplo de questões a serem trabalhadas: Qual a relação entre o programa de pesquisa de Laplace e a aceitação da teoria corpuscular? Como questões políticas (política científica) influenciaram no desenvolvimento e aceitação das teorias científicas, no período histórico analisado?

- A ciência como parte de uma cultura mais ampla (cultura científica/pressupostos epistemológicos do período): dentro deste tema, podemos destacar as semelhanças e diferenças entre a cultura científica existente entre os britânicos e a cultura científica entre os franceses. Exemplo de questões a serem trabalhadas: Como os pressupostos epistemológicos aceitos pela comunidade científica do período influenciaram as pesquisas sobre a natureza da luz desenvolvidas por estudiosos dessa comunidade?

- Comunicação do conhecimento científico dentro da comunidade científica e em domínio público: pode-se discutir as dificuldades existentes no processo de divulgação das teorias entre os pares, bem como discutir como o processo de divulgação de trabalhos científicos leva a modificações em sua estrutura. $\mathrm{O}$ trabalho de Fresnel sobre difração, por exemplo, sofreu diversas modificações quando foi publicado na Annales de chimie et de physique. Exemplo de questões a serem trabalhadas: Como ocorria o processo de divulgação entre os pares? Como grupos políticos influenciaram na publicação de trabalhos científicos?

- Controvérsias históricas e contemporâneas na ciência: o episódio, em si, retrata uma controvérsia entre duas grandes teorias sobre a natureza da luz no início do século XIX, mostrando o quão complexo é o desenvolvimento e a aceitação de uma teoria (teoria ondulatória), influenciado por diversos fatores e associado ao contexto em que está sendo desenvolvido. Além disso, o episódio evidencia que diversos estudiosos, frequentemente, discordam entre si, tanto em relação a aspectos científicos quanto a pressupostos epistemológicos. 
Exemplo de questões a serem trabalhadas: As controvérsias, a exemplo da que trata o episódio, estão sempre presentes no desenvolvimento do conhecimento científico?

Dentro do eixo epistemológico, podemos discutir os seguintes temas:

- Papel da observação, experimentação, lógica, argumentos racionais e pensamento teórico: o papel da experimentação no processo de construção da ciência pode ser problematizado a partir da análise da importância dada à experimentação no processo de construção do conhecimento científico pelos estudiosos da época, especialmente entre os britânicos. Exemplo de questões a serem trabalhadas: Como o ideal de comprovação experimental predominante entre os britânicos influenciou no desenvolvimento dos trabalhos científicos desenvolvidos por estudiosos dessa comunidade?

- Influências teóricas sobre observações e experiências: 1) as observações feitas por estudiosos da época eram guiadas pelas teorias que eles aceitavam, assim, pode-se discutir o papel das influências teóricas sobre observações e experiências; 2) o ideal do programa laplaciano de pesquisa de explicar os fenômenos a partir de forças à distância entre partículas permeava as explicações sobre os fenômenos luminosos dentro desse programa. Exemplo de questões a serem trabalhadas: A teoria influencia a observação dos fenômenos e/ou a análise de experimentos? Há observações "neutras"?

- Observação e inferência: estudiosos da época, observando os mesmos fenômenos, mas guiados por concepções teóricas diferentes, faziam diferentes inferências a partir do fenômeno observado, por exemplo, as diferenças nas explicações das franjas de difração entre os corpuscularistas e os ondulacionistas do período. Dessa maneira, pode-se discutir a diferença entre observação e inferência no estudo dos fenômenos. Exemplo de questões a serem trabalhadas: Por que as explicações para o fenômeno de difração diferiam entre os corpuscularistas e os ondulacionistas?

- Hipóteses, previsões e testes: 1) podemos discutir que a ciência nem sempre segue o modelo, amplamente difundido, de fazer hipóteses e delas retirar previsões que devem ser submetidas a testes experimentais, debatendo os diferentes caminhos que os estudiosos envolvidos nos estudos sobre a natureza da luz seguiam em seus trabalhos; 2) o uso de hipóteses no processo de construção do conhecimento não era bem aceito entre os britânicos, no início do século XIX. Exemplo de questões a serem trabalhadas: Qual o papel das hipóteses na construção das teorias sobre a natureza da luz?

- Avaliação de teorias: a complexidade existente no processo de avaliação de teorias científicas também pode ser trabalhada. $\mathrm{O}$ episódio em si retrata a controvérsia existente entre a teoria ondulatória e a teoria corpuscular da luz no início do século XIX, evidenciando que a avaliação pelos estudiosos da época entre essas duas teorias não era algo simples, direto e objetivo, mas algo que levou décadas até um desfecho e que envolveu diversos fatores nessa avaliação, além de fatores científicos. Exemplo de questões a serem trabalhadas: Como ocorreu o processo de avaliação entre as teorias corpuscular e ondulatória da luz, no período histórico analisado? Quais fatores influenciaram no processo de avaliação entre essas teorias? 
- Papel das analogias, imaginação e criatividade: o papel das analogias no processo de construção do conhecimento científico pode ser discutido a partir dos trabalhos de Thomas Young sobre a natureza da luz. Em seus trabalhos, Young utiliza recorrentemente analogias para explicar diversos fenômenos luminosos. Exemplo de questões a serem trabalhadas: Qual papel da analogia com o som na construção da teoria ondulatória de Young?

- Visão do senso comum sobre o método científico (sequência passo-a-passo): a ideia de que não existe um padrão único de fazer ciência também pode ser explorada, uma vez que os estudiosos envolvidos nos estudos sobre a natureza da luz, em uma mesma época, defendiam diferentes meios para a construção do conhecimento. Enquanto uns não admitiam o uso de hipóteses, por exemplo, outros as consideravam válidas no processo de construção do conhecimento. Exemplo de questões a serem trabalhadas: Existia um padrão único de construção do conhecimento, no episódio analisado? A ciência segue um método padrão em sua prática?

- Poder e limitações do conhecimento científico: as limitações do conhecimento científico também podem ser discutidas, uma vez que as teorias da luz, mesmo que predominantes no período, não conseguiam dar conta de explicar todos os fenômenos conhecidos. Por exemplo, a teoria ondulatória, mesmo na década de 1830, ainda não conseguia explicar o fenômeno de dispersão. Exemplo de questões a serem trabalhadas: $\mathrm{O}$ conhecimento científico pode ser provado? Ele é definitivo ou pode sofrer alterações ao longo do tempo? O que episódio histórico trouxe de contribuições para respondermos a isso?

\section{III.3 Temas de NDC obtidos na segunda etapa de análise}

Em nossa segunda etapa de análise, identificamos dois temas de NDC que podem ser trabalhados a partir do episódio histórico e que não estão presentes entre os temas de NDC propostos em Martins (2015). São eles:

- Conexão entre áreas da ciência: a ciência não deve ser vista como composta por áreas que não tem conexão, mas como um todo integrado. Por exemplo, observamos que os estudos de Young sobre a natureza da luz estavam relacionados a seus estudos sobre o som, acústica e acomodação visual. Os estudos sobre a teoria ondulatória da luz impulsionaram, a partir da década de 1830, os estudos sobre a teoria ondulatória de calor radiante. Dessa maneira, podemos problematizar a visão exclusivamente analítica da ciência, mostrando que os estudos na ciência estão inter-relacionados. Exemplo de questões a serem trabalhadas: Qual a relação entre os estudos sobre a natureza da luz e os estudos sobre a natureza do calor, no período histórico analisado?

- Atividades Profissionais: os cientistas não devem ser vistos como gênios que trabalham isolados em seus laboratórios. O episódio histórico permite enfatizar que os estudiosos de uma determinada época participavam de outras atividades profissionais além de desenvolver suas pesquisas, como: 1) participavam de sociedades e academias científicas, a exemplo da Academia de Ciências e da Sociedade de Arcueil, em Paris, e da Associação Britânica para 
o Avanço da Ciência e da Royal Society, entre os britânicos; 2) participavam de disputas por cargos científicos, bem como competições de prêmios organizadas por essas sociedades e academias. Exemplo de questões a serem trabalhadas: Os estudiosos envolvidos nas discussões sobre a natureza da luz desenvolviam apenas atividades eminentemente científicas?

\section{Considerações finais}

Sobre o estudo histórico, podemos destacar a complexidade envolvida no processo de buscar compreender um episódio tão rico de informações e permeado por diversos fatores quanto às discussões sobre a natureza da luz no início do século XIX.

Ressaltamos, ainda, que os aspectos apontados para a utilização do episódio histórico na discussão de temas de NDC dependem, em grande parte, dos recortes adotados no momento de estudo do episódio histórico. Nesse sentido, salientamos a impossibilidade de um estudo totalmente imparcial de determinado momento da História da Ciência, uma vez que as escolhas do historiador, suas interpretações, dentre outros aspectos, vão influenciar na narrativa histórica final.

Em relação à problematização dos temas de NDC, a complexidade envolvida nos debates teoria ondulatória versus teoria corpuscular da luz, no período estudado, mostrou-se muito rica do ponto de vista da seleção de temas para discussão de aspectos da NDC. A análise do material histórico evidenciou a possibilidade de trabalharmos diversos temas da NDC, tanto relacionados ao eixo histórico e sociológico quanto ao eixo epistemológico, com ênfase nos vários fatores envolvidos no desenvolvimento do conhecimento científico, e que podem ser problematizados no ensino de física.

Salientamos a importância de abordar os temas de NDC por meio de questões, na medida em que elas enfatizam o caráter investigativo que o tratamento dos temas deve adotar, de modo a envolver ativamente os estudantes na reflexão sobre os aspectos de NDC trabalhados.

Cabe ainda destacar que os aspectos apontados para a utilização do episódio histórico quanto à NDC não se esgotam aqui, uma vez que os temas e questões de NDC abordados anteriormente não são estáticos, mas dependem, em grande parte, de como o episódio é abordado em sala de aula e da problematização que é promovida.

Por fim, ressaltamos que foi realizada uma intervenção didática em nível superior, por meio da criação de uma narrativa histórica, que teve como objetivo investigar as potencialidades e limitações de trabalhar temas de NDC com professores de Física em formação inicial, tomando como base os debates sobre a natureza da luz no início do século XIX. Por sua extensão, o rico processo de desenvolvimento e a análise dessa etapa da pesquisa não podem ser aqui apresentados e serão detalhados em outro trabalho, ainda em construção.

Porém, cabe ressaltar que a intervenção didática usando a narrativa requer a superação de obstáculos na formação do professor já destacados em outras pesquisas (FORATO, 2009, SILVA, 2010; VIEIRA, 2014), como: conhecer alguns pressupostos básicos da histori- 
ografia que podem auxiliar na inserção da HFC no ensino de ciências (tal cautela é imprescindível para que não se caia na armadilha da mera apresentação de datas e nomes, sem a devida contextualização histórica); superar concepções inadequadas (empiristas-indutivistas) sobre a NDC; superar o papel do professor como mero transmissor de conteúdos, adotando uma postura de mediador, favorecendo o debate e a argumentação por parte dos estudantes, de modo a transpor o dogmatismo geralmente presente no ensino de ciências, dentre outros.

\section{Referências}

BRASIL. Parâmetros Curriculares Nacionais para o Ensino Médio. Parte III - ciências da natureza, matemática e suas tecnologias. Brasília, DF: MEC/SEF, 1999.

BRASIL. Diretrizes Nacionais Curriculares para os Cursos de Física. Brasília, DF: MEC/SEF, 2001.

BRASIL. Base Nacional Comum Curricular - Ensino Médio - BNCC. Brasília, DF: Ministério da Educação, 2018.

CANTOR, G. N. Optics after Newton - theories of light in Britain and Ireland, 1704-1840. Manchester: Manchester University Press, 1983. 257 p.

CHEN, X. Theories, Experiments, and Human Agents: The Controversy between Emissionists and Undulacionists in Britain, 1827-1859. 1992. 373 f. Dissertação (Doctor of Philosophy in Science and Technology Studies) - Virginia Polytechnic Institute and State University Blacksburg, Virginia.

DARRIGOL, O. The history of optics: from Greek antiquity to the nineteenth century. Oxford: University Press, 2012. 344 p.

FORATO, T. C. M. A natureza da ciência como saber escolar: um estudo de caso a partir da história da luz. 2009. 220 f. Tese (Doutorado em Educação) - Faculdade de Educação, Universidade de São Paulo, São Paulo.

FORATO, T. C. M.; MARTINS, R. A.; PIETROCOLA, M. History and Nature of Science in High School: Building up Parameters to Guide Educational Materials and Strategies. Science \& Education, v. 21, n. 5, p. 657-682, 2012.

FOX, R. The rise and fall of Laplacian physics. Historical Studies in the Physical Sciences, v. 4, p. 89-136, 1974. 
FRANKEL, E. Corpuscular Optics and the Wave Theory of Light: The Science and Politics of a Revolution in Physics. Social Studies of Science, v. 6, p. 141-184, 1976.

FRANKEL, E. Biot and the Mathematization of Experimental Physics in Napoleonic France. Historical Studies in the Physical Sciences, v. 8, p. 33-72, 1977.

FRESNEL, A. Memoir on the diffraction of Light (1819). Tradução: Henry Crew. In: CREW, H. The Wave Theory of Light: Memoirs by Huygens, Young e Fresnel. Woodstock: American Book Company, 1900. p. 81-144.

GILLISPIE, C. C. Pierre-Simon Laplace. In: GILLISPIE, C. C. Dicionário de biografias científicas. Tradução: Carlos Almeida Pereira et al. Rio de Janeiro: Contraponto, 2007, p. 1431-1557. v. 2.

IRZIK, G.; NOLA, R. New Directions for Nature of Science Research. In: MATTHEWS, M. R (Ed.). International Handbook of Research in History, Philosophy and Science Teaching. New York: Springer, 2014. p. 999-1022.

JAMES, F. A. J. L. The Physical Interpretation of the Wave Theory of Light. The British Journal for the History of Science, v. 17, n. 1, p. 47-60, 1984.

JUNGES, A. L.; MASSONI, N. T. O Consenso Científico sobre Aquecimento Global Antropogênico: Considerações Históricas e Epistemológicas e Reflexões para o Ensino dessa Temática. Revista Brasileira de Pesquisa em Educação em Ciências, v. 18, n. 2, p. 455-491, 2018.

KOEHLER, C. B. G.; CAMEL, T. O.; PIMENTEL JR, R. A. Éter e Estrutura da Matéria no Século XIX. In: SEMINÁRIO NACIONAL DE HISTÓRIA DA CIÊNCIA E DA TECNOLOGIA, 2012. Atas...

LEVITT, T. Editing out Caloric: Fresnel, Arago and the Meaning of Light. The British Journal for the History of Science, v. 33, n. 1, p. 49-65, 2000.

MARTINS, A. F. P. Natureza da ciência no ensino de ciências: uma proposta baseada em "temas" e "questões". Caderno Brasileiro de Ensino de Física, v. 32, n. 3, p. 703-737, 2015.

MATTHEWS, M. R. Science teaching - The role of History and Philosophy of Science. New York: Routledge, 1994. 
MATTHEWS, M. R. Changing the Focus: From Nature of Science (NOS) to Features of Science (FOS). In: KHINE, M. S. (Ed.). Advances in Nature of Science Research: Concepts and Methodologies. New York: Springer, 2012. p. 3-27.

MORSE, E. W. Thomas Young. In: GILLISPIE, C. C. Dicionário de biografia científicas. Tradução: Carlos Almeida Pereira et al. Rio de Janeiro: Contraponto, 2007, p. 2663-2672. v. 3.

MOURA, B. A.; BOSS, S. L. B. Thomas Young e o resgate da teoria ondulatória da luz: Uma tradução comentada de sua Teoria Sobre Luz e Cores. Revista Brasileira de Ensino de Física, v. 37, n. $4, n^{\circ} 4203,2015$.

MOURA, B. A. A Aceitação da Óptica Newtoniana no Século XVIII: Subsídios para discutir Natureza da Ciência no Ensino. 2008. 214 f. Dissertação (Mestrado em Ensino de ciências) - Instituto de Física, Universidade de São Paulo, São Paulo.

MOURA, B. A. O que é natureza da ciência e qual sua relação com a História e Filosofia da ciência? Revista Brasileira de História da Ciência, Rio de Janeiro, v. 7, n. 1, p. 32-46, 2014.

OLIVEIRA, R. A. Natureza da Ciência por meio de narrativas históricas: os debates sobre a natureza da luz na primeira metade do século XIX. 2019. 232 f. Tese (Doutorado em Ensino de Ciências e Matemática) - Centro de Ciências Exatas e da Terra, Universidade Federal do Rio Grande do Norte, Natal.

RUDGE, D. W.; HOWE, E. M. An explicit and reflective approach to the use of History to promote understanding of the nature of Science. Science \& Education, v. 18, n. 5, p. 561$580,2009$.

SILLIMAN, R. H. Fresnel and the Emergence of Physics as a Discipline. Historical Studies in the Physical Sciences, v. 4, p. 137-162, 1974.

SILLIMAN, R. H. Augustin Fresnel. In: GILLISPIE, C. C. Dicionário de biografias científicas. Tradução: Carlos Almeida Pereira et al. Rio de Janeiro: Contraponto, 2007. p. 860-866. v. 1.

SILVA, B. V. C. Controvérsias sobre a natureza da luz: uma aplicação didática. 2010. 180 f. Dissertação (Mestrado em Ensino de Ciências Naturais e Matemática) - Centro de Ciências Exatas e da Terra, Universidade Federal do Rio Grande do Norte, Natal. 
VIEIRA, P. C. Perspectivas sobre a evolução histórica do conceito de luz e sua integração com a fotografia para o ensino da óptica. 2014. 228 f. Dissertação (Mestrado em Ensino de Física) - Universidade Federal do Rio Grande do Sul, Porto Alegre.

YOUNG, T. Outlines of experiments and inquiries respecting sound and light. Philosophical Transactions, v, 90, p. 106-150, 1800.

YOUNG, T. The Bakerian Lecture: On the Theory of Light and Colours. Philosophical Transactions, v. 92, p. 12-48, 1802a.

YOUNG, T. An Account of Some Cases of the Production of Colours, not Hitherto Described. Philosophical Transactions, v. 92, p. 387-397, 1802 b.

YOUNG, T. The Bakerian Lecture: Experiments and Calculations Relative to Physical Optics. Philosophical Transactions, v. 94, p. 1-16, 1804. 